Journal of Social Sciences 7 (4): 632-634, 2011

ISSN 1549-3652

(C) 2011 Science Publications

\title{
Managerial Decision and Resource Reallocation: A Dynamic Capability Perspective
}

\author{
${ }^{1}$ Jui-Mei Yien, ${ }^{2}$ Kuo-Hsiung Chen, ${ }^{3}$ Kai-Ping Huang and ${ }^{4}$ Chien-Jung Huang, \\ ${ }^{1}$ Department of Leisure Management, University of Kang Ning, Taiwan \\ ${ }^{2}$ Department of Business Administration, Cheng Shiu University, Taiwan \\ ${ }^{3}$ School of Management, University of Technology, Sydney, Australia \\ ${ }^{4}$ Department of Marketing and Distribution Management, \\ Fortune Institute of Technology, Taiwan
}

\begin{abstract}
Problem statement: The study has mainly been created to present a study on the significance of dynamic capability thereby stressing on the factors that can be dealt with in organizations through the use of dynamic capabilities. Approach: The literature review illustrates the effects of dynamic capabilities on managerial decisions and resource allocation. Results: The study reveals that the use of dynamic capabilities enables an organization to use strategic measures that prevent them for negative impacts; rather they are assisted through the availability of appropriate measures in achievement of organizational goals. Dynamic capabilities have shown to focus on appropriate selection and allocation of resources and decision making by the organizational leaders and managers. Conclusion: The study of dynamic capability can be said to be an important contribution in the researches made on organizational issues and for the success of different companies.
\end{abstract}

Key words: dynamic capabilities, resource-based view, managerial decision

\section{INTRODUCTION}

A resource-based view of a firm aids in the development of theory on the dynamic capabilities of the firm. As different resource-based views reflect, organizations may be capable of achieving competitive advantage on a continuous basis through the availability of resources that are important, exceptional, incomparable and that which cannot be substituted. As it can be obtained from different studies, dynamic capabilities are "the capacity of an organization to purposefully create, extend, or modify its resource base" (Ambrosini et al., 2009). Dynamic competitive capabilities offer value for a long period of time comprising competitive advantages obtained from customs and policies of different organizations. Organizational success depends to a large extent on the short term plans and routines that get incorporated to form bigger plans for the overall organizational objectives and goals (Chen et al., 2009).

This report is mainly focused on the performance of a firm through managerial decisions from the perspective of dynamic capabilities, thus pulling out the ability of a firm to succeed through strategic planning that are facilitated by dynamic capabilities.
Literature review and proposition development: Dynamic capabilities and managerial decision: The most important managerial decision in a firm is to allocate resources that involve allocation of finances, human resources, assets, products, services, customers, distribution and every other feature that lead to a firm's success. The resource allocation processes of an organization can be viewed as a dynamic capability since these processes have a major participation in "strategic renewal" having positive effects on the organizations of "resources and capabilities" that are intended for long-term perspectives and "far-reaching" effects (Coen and Maritan, 2011). Strategic decision makers are mostly involved and take the concern to help organizations in their accomplishments of "differential performance" (Allred et al., 2011). Several researchers have analyzed the importance of dynamic capabilities and collaborations as a resource that is capable of reducing conflicts arising from functional and organizational issues within organizations. It also provides advancements in the growth of "a distinctive relational advantage" (Allred et al., 2011). Management scholars believe that dynamic capabilities within organizations can take a major role in the performance of the firm and several researches have been conducted 


\section{J. Social Sci., 7 (4): 632-634, 2011}

to improve the concepts and understandings of the different types of capabilities that facilitate the decision making capabilities of the organizational managers (Drnevich and Kriauciunas, 2011).

The different researches have clearly indicated how dynamic capabilities play a significant role in the decision-making process of organizational managers. Dynamic capabilities enable the organizational managers to decide on the appropriate selection and allocation of available resources. Decisions in relation to investments, human resources and other organizational issues are also the major concerns of the managers. Such decisions are significant for a firm in accomplishing the organizational objectives. Dynamic capabilities through their innovativeness aid the managers and leaders of an organization to effectively take such decisions considering all probable hindrances and opportunities. Thus, dynamic capabilities have been obtained to be positively related to managerial decisions and this proposition is constantly developing towards betterment of organizational performance. That is:

Proposition one: Dynamic capabilities are positively related to managerial decisions

Dynamic capabilities and resource reconfiguration: If the resource-based view of an organization is considered, then it can be observed that the competitive advantage of the firm is dependent on the "creation, sustenance and continuous improvement of the core competencies" that have been created through the availability and effective and efficient allocation of the resources (Nobre and Walker, 2011). Dynamic capabilities with respect to a resource-based perspective imply that firms are varied in terms of their availability of resources and capabilities. Managerial strategies are considered in the resource-based views of a firm that lead to development of new capabilities. However, it is only recently that researchers have been focusing on the understandings of "firm-specific capabilities" and how the resource-based views and competencies "respond to shifts in the business environment" (Teece et al., 1997). As researchers have argued on the RBV, two specific aspects come in front. One reflects the heterogeneous availability of resources within organizations. The other is that certain resources that enable the achievement of competitive advantage are many times "embedded in inter-firm resources and routines" (Allred et al., 2011).

The dynamic capabilities having a resource-based view have immense attention on the resource reconfiguration dealing with the available resources in a firm. It believes in the success of a firm that possesses valuable, rare, inimitable and non-substitutable resources. Such firms are expected to perform better than their competitors and gain a competitive advantage over others. Dynamic capabilities can be observed to have a positive relationship with resource reconfiguration since in the global business world of competition; mere existence of resources cannot suffice the increasing needs and demands of the market. Dynamic capabilities enhance the ability of a firm to capitalize on the availability of the resources intended towards achievement of goals and objectives. Thus this proposition is also developing in the current scenario of business world. The following proposition then emerges:

Proposition two: Dynamic capabilities are positively related to resource reconfiguration

\section{CONCLUSION}

Different scholars have presented their studies reflecting the importance of organizational leaders and managers, who have a major participation in the outcomes of the business. They take the most important part by taking the all the necessary decisions of the company, depending on which the firm attains its goals and objectives. Leadership and management have thus been focused as important integral parts of dynamic capabilities of a firm, by several authors (Martin, 2011). All these studies and the ones discussed in the literature review indicate that there are tremendous opportunities to make further researches on the dynamic capabilities and their significance in business organizations. New researchers may make use of the earlier studies and associate them with newer issues that may be prominent as difficulties for organizational success. Particularly in a changing business environment, it is highly necessary for each and every organization to undertake innovative strategies that are focused to the organizational objectives as well as the needs and expectations of the customers. Thus further researches may be expected to enhance the understanding of the different issues in relation to dynamic capabilities and find out new measures towards achievement of organizational success.

The different studies conducted and the analysis made on them give a clear picture of the advantages that dynamic capabilities provide the different organizations with. The primary intention of dynamic capabilities within organizations is to provide the firm with the strategies and measures that would enable it to efficiently and effectively handle the different circumstances that may hinder the attainment of organizational goals. It is mainly focused on the resources available within the company that may be utilized optimally and successfully towards 
organizational achievement. The use of dynamic capabilities within organizations tends to provide a firm with long-term success through the formulation of different strategies.

Although it has been obtained by some researchers that certain details of the studies on dynamic capabilities have not been conducted yet; however, the relevance of the dynamic capabilities in organizations can be understood from the studies that have reflected the improvements that firms experience with the possession of such capabilities. Allocation of resources that have a significant impact on the organizational performance is efficiently managed by dynamic capabilities. Market information is also made available to managers who can analyze them to further decide on their ventures. Managerial strategies are well thoughtout in the resource-based views of a firm that direct a way to advancement of new capabilities.

\section{REFERENCES}

Allred, C.R., S.E. Fawcett, C. Wallin and G.M. Magnan, 2011. A dynamic collaboration capability as a source of competitive advantage. Decision Sci., 42: 129-161. DOI: $10.1111 / j .1540-$ 5915.2010.00304.x

Ambrosini, V., C. Bowman and N. Collier, 2009. Dynamic capabilities: An exploration of how firms renew their resource base. Br. J. Manag., 20: S9S24. DOI: 10.1111/j.1467-8551.2008.00610.x
Chen, H.H., P.Y. Lee and T.J. Lay, 2009. Drivers of dynamic learning and dynamic competitive capabilities in international strategic alliances. J. Bus. Res., 62: 1289-1295. DOI: 10.1016/j.jbusres.2008.12.003

Coen, C.A. and C.A. Maritan, 2011. Investing in capabilities: The dynamics of resource allocation. Organ. $\quad$ Sci., 22: 99-117. DOI: 10.1287/orsc. 1090.0524

Drnevich, P.L. and A.P. Kriauciunas, 2011. Clarifying the conditions and limits of the contributions of ordinary and dynamic capabilities to relative firm performance. Strategic Manag. J., 32: 254-279. DOI: $10.1002 / \mathrm{smj} .882$

Martin, J.A., 2011. Dynamic managerial capabilities and the multibusiness team: the role of episodic teams in executive leadership groups. Organ. Sci., 22: 118-140. DOI: $10.1287 /$ orsc. 1090.0515

Nobre, F.S. and D.S. Walker, 2011. An ability-based view of the organization: Strategic-resource and contingency domains. Learn. Organ., 18: 333-345. DOI: 10.1108/09696471111132531

Teece, D.J., G. Pisano and A. Shuen, 1997. Dynamic capabilities and strategic management. Strategic Manag. J., 18: 509-533. DOI: 10.1002/(SICI)10970266(199708)18:7<509::AID-SMJ882>3.0.CO;2-Z 